\title{
Gambling, Geographical variations and deprivation: findings from the Adult Psychiatric Morbidity Survey
}

\author{
Giuseppe Carrà a,b $^{\text {,b }}$ Cristina Crocamo ${ }^{\text {b }}$, Paul Bebbington ${ }^{\text {a }}$
}

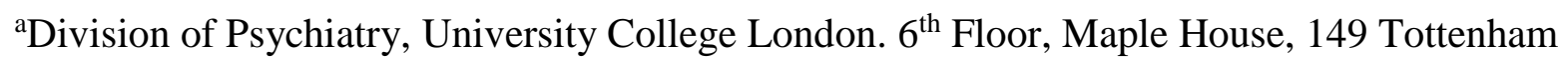
Court Road, London W1T 7NF, UK. giuseppe.carra@ unimib.it; p.bebbington@ucl.ac.uk ${ }^{\mathrm{b}}$ Department of Medicine and Surgery, University of Milano Bicocca, Via Cadore 48, 20900 Monza (MB), Italy. cristina.crocamo@unimib.it

\section{Brief manuscript resubmitted for publication to International Gambling Studies}

Running Head: Gambling geographical variations in the UK

Word count: Manuscript 2730; Abstract 188; Tables 2.

\section{Address for correspondence}

Cristina Crocamo, PhD. Department of Medicine and Surgery, University of Milano Bicocca. Via Cadore, 48 - 20900 Monza, Italy. Tel/Fax +39 0392332277.

E-mail address cristina.crocamo@unimib.it

\section{Short biographical notes}

Giuseppe Carrà, MD, MSc, $\mathrm{PhD}$, is a Researcher in Psychiatry at University of MilanoBicocca and a Research Fellow at the Division of Psychiatry UCL, London. His main research interests include Dual diagnosis, Social Psychiatry and Psychiatric Epidemiology. Fellow of the International Society of Addiction Medicine, he co-edited the Textbook of Addiction Treatment: International Perspectives. He served in several expert panels for a number of National and International institutions. His current publications record includes more than 100 peer-reviewed articles in high impact factor scientific Journals.

Cristina Crocamo, MSc, $\mathrm{PhD}$, is a post-doctoral fellow in the field of Medical Statistics, Clinical Epidemiology, and Public Health at the University of Milano-Bicocca, with main research interests related to mental health, addiction, comorbidity, and eHealth. She collaborated in many projects in the field of Addiction exploring mechanisms that could increase awareness of subjects on addiction issues. She co-authored several publications in peer-reviewed scientific journals and she also serves as an advisor for analysis of medical data, effectively interfacing with medical students.

Paul Bebbington, MA, MPhil, PhD, FRCP, FRCPsych, is Professor Emeritus at UCL.

Professor Bebbington continues to publish extensively on epidemiological issues, on mental health services, and on psychological theories and treatments of psychosis. With colleagues 
he has conducted a number of randomized controlled trials of psychiatric interventions and psychological treatments. He was instrumental in the organization and design of all four British National Surveys of Psychiatric Morbidity (1993-2014). He was the founding editor of the International Review of Psychiatry, and was the Editor-in-Chief of Social Psychiatry and Psychiatric Epidemiology from 1993 until 2013.

\section{Acknowledgements}

We would like to thank all the respondents who so generously gave up their time to participate in this survey and to acknowledge the enormous professionalism and commitment of the NatCen and Sally McManus, who led on the first phase of the APMS.

\section{Role of Funding Source}

Funding for this study was provided in part by the Department of Health, which had no role in the study design, collection, analysis or interpretation of the data, writing the manuscript, or the decision to submit the paper for publication.

\section{Conflict of interest}

The authors declare that they have no conflict of interest. 


\title{
Gambling, Geographical variations and deprivation: findings from the Adult Psychiatric Morbidity Survey
}

\begin{abstract}
Gambling problems are prevalent in the UK, especially in the most deprived boroughs of the country. Individual level characteristics may exist alongside a social and geographical gradient. We aimed to establish whether living in specific geographic areas increases problem gambling likelihood.

We used data from the 2007 Adult Psychiatric Morbidity Survey. We adopted a twofold categorization distinguishing recreational from problem/pathological gambling. We used the 2004 Overall Index of Multiple Deprivation to measure deprivation of the district of residence, and primary sampling units, based on postcode sectors, to take into account area characteristics in multilevel mixed-effects regression models.

The determinants of recreational gambling operated solely at the individual level. These included male sex, stable relationship and employment, though a number of clinical variables were also important: impulsivity, hazardous use or dependency on alcohol, and current smoking. In contrast, an appreciable proportion of the variance in problem/pathological gambling was explained by area-level clustering.

Unlike recreational gamblers, problem/pathological gamblers appear to cluster in specific areas. Thus, there are grounds for restricting the location and density of gambling opportunities and for providing selective prevention programs targeting geographic areas characterized by contextual determinants.
\end{abstract}

Keywords: Gambling, Addictive behaviours, Socioeconomic Factors, Great Britain, Epidemiology, Deprivation 


\section{Introduction}

Although evidence on increasing rates of problem gambling in the UK (Wardle et al., 2011; Cowlishaw \& Kessler, 2016) are somehow contradictory, with various surveys reporting even a slight decrease (Wardle et al., 2014b), national estimates may not capture variations in rates associated with contextual characteristics. As with other levels of addictive behaviours (e.g., Gruenewald, 2007), individual-level characteristics may exist alongside a social and geographical gradient, with those living in areas of greater deprivation being more likely to experience gambling harm (Wardle, Keily, Astbury, \& Reith, 2014a). Recently, there has been public debate in the UK about the concentration of fixed odds betting terminals in the most deprived boroughs (Astbury \& Turstain-Goodwin, 2015; Fairer Gambling, 2015). Great Britain has one of the most open gambling markets worldwide, including lottery tickets from local retailers, machines placed in a variety of locations, casinos, bookmakers and online systems (Wardle et al., 2011).

Previous studies from Australia and New Zealand showed that problem gambling is frequently clustered in areas of greater deprivation, and is associated with lower individuallevel socio-economic characteristics (Livingstone, 2001; Wheeler, Rigby, \& Huriwai, 2006). However, these areas are also those with an excess provision of gambling outlets. Poverty may cause stress and negative affective states, leading to risk-averse decision-making, probably by limiting attention, backing unhealthy behaviours and compromising goal-directed activities (Haushofer \& Fehr, 2014). Thus, poverty is often associated with higher financial risk-taking attitudes, based on the psychoeconomics of gambling, since people living in poverty see greater possibility to improve their condition from a gambling gain than affluent subjects (Shaffer \& Korn, 2002).

Recent research has established the association of problem gambling with indicators of mental and physical health, as well as psychosocial adjustment and health care usage (Cowlishaw \& Kessler, 2016). Interestingly, various degrees of problem gambling seem to be associated with different individual-level correlates. For example, problem gambling is associated with recent drug use, anxiety disorders, and suicidal ideation, which was not the case for milder levels of gambling. Thus, non-individual characteristics may play an important role in determining more severe gambling behaviours. In particular, it seems important to assess whether arealevel characteristics, which are appropriately distinguished from individual-level factors by means of multilevel mixed-effect modelling, are important determinants of recent (past year) problem and pathological gambling. 
Overall, there is likely to be a complex social and geographical patterning of gambling, involving individual as well as social factors (Pearce, Mason, Hiscock, \& Day, 2008). The 2007 Adult Psychiatric Morbidity Survey provides data on gambling and also measures of area deprivation in a representative sample of the English general population. This enabled us to test the hypotheses that living in certain geographic, especially deprived areas increases levels of gambling, and that this will especially affect problematic gambling.

\section{Methods}

\section{Setting and participants}

General descriptions of the design and methods used in the 2007 Adult Psychiatric Morbidity Survey (APMS) have been provided elsewhere (McManus, Meltzer, Brugha, \& Bebbington, 2009). In brief, the survey used stratified, random probability sampling. Private households were identified from the small user Postcode Address File (PAF), which covers all post office delivery points receiving fewer than 50 items of mail each day. This provides a comprehensive database of private households in England. The primary sampling units (PSUs) were individual or grouped postcode sectors, stratified by region. Professional survey interviewers conducted detailed interviews largely based on standardized instruments. The achieved sample comprised 7403 respondents, representative of the population living in private households in England, aged 16 and over. Ethical approval for APMS 2007 was obtained from the Royal Free Hospital and Medical School Research Ethics Committee.

\section{Main outcome measure and individual-level covariates}

Previously published work from APMS 2007 (Cowlishaw \& Kessler, 2016) has reported low rates both of problem gambling (weighted prevalence $0.7 \%, 95 \% \mathrm{CI} 0.5-1.0$ ), and of pathological gambling (weighted prevalence $0.3 \%, 95 \%$ CI $0.2-0.5$ ). In the current report, we summed items from a questionnaire based on the ten DSM-IV diagnostic criteria for pathological gambling in the past year. We distinguished respondents scoring 1 or 2 on the DSM-IV questionnaire as recreational gamblers, from those who reported problem or pathological gambling ( $\geq 3$ criteria). We dealt with relevant missing data, following APMS derived variables specifications. Thus, we excluded from the analysis "not applicable cases" $(\mathrm{N}=75)$. Then, we distinguished and excluded those who scored higher than 5 on missing DSM-IV responses, while those who had missing DSM-IV responses $\leq 5$ were included in the analysis, scoring missing items as zero for summing. Along with sociodemographic variables, including estimates of equivalised household annual total income and financial difficulties, 
we chose a number of measures as covariates. The measure of unemployment used combined those who were economically inactive (e.g., pensioners, carers, stay at home partners) and respondents seeking employment. Self-rated general health was derived from a single item of the Short Form-12 health index (SF-12) (Brazier \& Roberts, 2004). Those scoring above 12 on the Revised Clinical Interview Schedule (CIS-R) (Lewis, Pelosi, Araya, \& Dunn, 1992) were regarded as suffering from a neurotic disorder. The CIS-R also provided information on suicidal thoughts and attempts. The presence of impulsivity was operationalised as a 'Yes' or 'No' response to the question 'Have you often done things impulsively?'. This has shown convergent and discriminate validity (Ryder et al., 2007), though it might be more related to urgency than to other UPPS dimensions (e.g., premeditation and perseverance), that are relevant in relation to the prevention and treatment of problem/pathological gambling (Whiteside \& Lyman, 2001). The UPPS model of impulsivity is a more suitable framework to help us understand the relationship between personality and problem/pathological gambling. Based on the UPPS model, impulsivity is an umbrella construct reflected by four distinct dimensions: negative urgency, premeditation, perseverance, and sensation-seeking, with negative urgency defined as the tendency to act rashly while faced with intense negative emotional contexts (emotion-laden impulsivity) (Canale, Vieno, Bowden-Jones, \& Billieux, 2017). Hazardous and harmful drinking was established using the Alcohol Use Disorders Identification Test (AUDIT) (Saunders, Aasland, Babor, Dela Fuente, \& Grant, 1993): a score of eight or more indicated hazardous drinking, while 16 or more indicated harmful drinking. Alcohol dependence was defined as a score of four or more on the Severity of Alcohol Dependence Questionnaire - community version (SADQC) (Stockwell, Sitharan, McGrath, \& Lang, 1994). Drug misuse was assessed from questions based on the Diagnostic Interview Schedule (Malgady, Rogler, \& Tryon, 1992). Misuse of any drug in the last year and current smoking were also recorded.

\section{Area-level covariate}

In order to measure area-level deprivation, we used the 2004 Overall Index of Multiple Deprivation (QIMD) (DCLG, 2004), a composite index at small area level, based on seven domains of relative deprivation: income; employment; health deprivation and disability; education, skills and training; barriers to housing and services; crime and disorder; and living environment. Scores were grouped into quintiles, quintile 1 being the least deprived. However, primary sampling units (PSUs) based on postcode sectors were also considered to 
take into account area characteristics: these are likely to affect the test results in a multilevel mixed-effects regression model.

\section{Statistical methods}

We carried out univariate analyses to establish associations between gambling and baseline individual and area-level characteristics in order to identify relevant covariates with less than $5 \%$ missing data. Bonferroni correction was used to deal with the issue of multiple testing. We then ran mixed effects models incorporating both individual and area-level effects on different levels of gambling. The available measure of area-level deprivation was ranked in five levels. However, at least 8/10 levels (depending on sizes of groups) are needed in multilevel mixed-effects logistic regression models (Austin, 2010) to examine the area effect on different levels of gambling. Thus, we used PSUs as area-level variable (random intercept), controlling for other potential individual factors, and included QIMD as a subjectlevel categorical predictor describing deprivation of the district of usual residence. We calculated residual intra-class correlation (ICC) to quantify the amount of area-level variance over the total variance. We compared the performances of different two-level models using Akaike Information Criterion (AIC) with the estat ic Stata command, also looking at a modified AIC, adjusting the log-likelihood and penalty term by the number of observations in the model (Hilbe, 2009). Due to potential missing data on the covariates, we estimated AIC considering the lowest sample size. Models with lower AIC values have better empirical support than those with higher values. Significance levels were set at 5\%. Analyses were performed using Stata statistical software package (version 14; StataCorp, College Station, Texas).

\section{Results}

Valid data were available from 7328 subjects. While 4815 (66\%) reported some degree of recreational gambling in the past year, many fewer had problem and pathological gambling: 22 and 19, respectively. Table 1 shows the characteristics of respondents with past year problem/pathological gambling, of recreational gamblers, and of non-gamblers.

Problem/pathological gamblers were significantly more often male; younger; single; with lower educational levels, and smaller social networks. Although relatively more likely to be in employment, they reported more financial difficulties in terms of debts and borrowing, despite a significantly higher household annual income. They also reported significantly more current smoking, hazardous alcohol use and dependency and other drug misuse, poor health, 
impulsivity, and suicide ideation and attempts. They were more likely to have a common mental disorder (CMD), and lived significantly more frequently in deprived areas.

\section{Table 1 about here}

Controlling for identified covariates, we then examined individual- (QIMD) and area-level (PSUs) components impact on different levels of gambling in mixed effect models. Table 2 presents the results of the multi-level analyses for both problem/pathological and recreational gambling.

\section{Table 2 about here}

In relation to problem/pathological gambling, the PSU level random term was statistically significant (estimate $=0.507, \mathrm{SE}=0.852$ ), showing that severe gambling was not uniformly distributed geographically: of the total residual variability, $13 \%$ was explained by PSU clustering. Of individual-level characteristics only male sex, impulsivity and drug misuse remained significant in this model, whilst there was a tendency for residence in the most deprived areas to be associated with problem/pathological gambling. The sequential addition to this model of individual-level age and gender; other sociodemographic correlates significant at univariate level; health and mental comorbid conditions; alcohol/substance correlates; and finally deprivation of the district of usual residence indicated that our initial choice of multilevel mixed-effect regression model was the best-supported. Considering an equal number of observations in each analysis, this model had the lowest AIC, ranging from 395.98 to 430.26. Thus, area characteristics in terms of PSUs contribute independently to problem/pathological gambling, explaining a moderate proportion of the variance.

Recreational gambling was evenly distributed across areas: only $3 \%$ of the total residual variability was explained by PSU clustering, with a non-significant random term (estimate $=0.95, \mathrm{SE}=0.029$ ). Thus, the vast proportion of the variance of recreational gambling was accounted for by individual level factors. Recreational gamblers were characteristically male and in a relationship. They tended to be in employment, though with financial difficulties and debt. In addition, clinical variables were important in explaining part of the variance: impulsivity, hazardous use or dependency on alcohol (though not on other drugs), and current smoking were all significantly associated with recreational gambling. Interestingly, this form of gambling was not associated with the presence of comorbid mental disorders.

\section{Discussion}


In this large, multilevel study of 7328 subjects from 519 PSUs, individual-level factors explained most of the variance in problem/pathological gambling. However, there were moderate but significant geographical variations, with severe gambling clustering in particular areas (13\%). At the individual level, male gender, impulsivity and drug misuse were also important determinants.

Our findings are largely consistent with the existing literature (e.g., Cowlishaw \& Kessler, 2016; Cowlishaw \& Hakes, 2015), with minor discrepancies relating to comorbid mental disorders (Grant \& Chamberlain, 2015). However, area-level factors had no significant impact on recreational gambling, which was associated with individual-level characteristics in line with other studies (Johansson, Grant, Kim, Odlaug, \& Götestam, 2009).

Thus, problem/pathological gambling may be associated with specific characteristics of certain PSUs. This is consistent with recent UK findings that specific geographic areas are associated with a high density of gambling machines (Wardle et al., 2014a). In the United States neighbourhood disadvantage was associated with higher gambling frequency in adults, and gambling venues were again more common in such neighbourhoods (Welte, Wieczorek, Barnes, Tidwell, \& Hoffman, 2004). Evidence from a large Canadian sample suggests that impulsivity is associated with gambling behaviours only in the context of area-level material deprivation, and that impulsivity is not an important determinant of gambling in socioeconomically advantaged subjects (Auger, Lo, Cantinotti, \& O'Loughlin, 2010). Finally, also recent Australian data confirmed an association between local area disadvantage and gambling behaviour (Slutske, Deutsch, Statham, \& Martin, 2015).

The mechanisms behind area effects should be considered. The greater density of gambling outlets in relatively disadvantaged neighbourhoods (Pearce et al., 2008) might be a successful commercial response to the vulnerability of local inhabitants, generating a vicious circle of increasing problem gambling. This vulnerability may be driven by social contagion in areas with a high proportion of inhabitants who gamble regularly (Christakis \& Fowler, 2013; Martins, Storr, Lee, \& Ialongo, 2013).

The large, epidemiologically representative, sample provided by the APMS 2007, has inherent limitations since it includes only one adult randomly selected for interview even if households contain more than one aged 16 or over. This has particular implications for the 1624 age group, likely to be under represented despite it shows significantly elevated levels of both problem and pathological gambling compared to older age groups (Jiménez-Murcia et al., 2010). As a whole, the number of problem/pathological gamblers was relatively small. We had to exclude subjects with more than 5 missing DSM-IV responses and data were collected 
early in the deployment of betting machines in gambling venues. Indeed, the dataset used is now over 10 years old. Since 2008, substantial changes have occurred in the UK gambling landscape, including full implementation of the recommendations of the 2005 Gambling Act (Miers, 2006). In addition, in particular in relation to geographic areas as correlates of problem gambling, it should be acknowledged the development of Internet and Mobile Gambling (Gainsbury, Russell, Hing, Wood, \& Blaszczynski, 2013) that is prevalent among UK young people (Griffiths, Wardle, Orford, Sproston, \& Erens, 2009), which could not be included in our sample. How the relationship between area-level deprivation and mobile gambling could be adequately studied remains a challenge, which might be addressed using specific mobile ecological momentary assessment, similarly to other addictive behaviours (Carrà et al., 2016). Thus, our findings should be considered in relation to the current, possibly different, gambling landscape in the UK, and with particular caution until replicated with appropriate methods that can include internet and mobile gamblers. Nonetheless, contextual determinants should be evaluated separately from availability (Wheeler et al., 2006; Pearce et al., 2008), as in the case of alcohol and drug problems (Mann, 2005; Carrà et al., 2017). Furthermore, the temporal relation between geographical area and gambling could not be established because of the cross-sectional nature of the study. Although area characteristics are likely to be stable, some of the subjects involved in more harming gambling may have been forced to move to disadvantaged areas by economic setback. Future research should explore also the relationship between area-level deprivation and gambling, exploring the potential mediating effect that clustering of gambling opportunities may play. In addition, our multilevel mixed-effects model uses a small sample of problem/pathological gambling $(\mathrm{N}=41)$, which is a general problem in the gambling literature. However, we had 14 covariates, though the general advice for regression models is 10:1 (Vittinghoff, \& McCulloch, 2007; Greenland, Mansournia, \& Altman, 2016; Pavlou et al., 2015). Thus, our model is likely to be overfitted, producing inflated or biased coefficients, with confidence intervals that can be overly conservative. This might explain some of the lack of fixed effects for several correlates, and more importantly for the PSU random effect ICC, that may be dependent upon. As a whole, it is unclear whether our study is capturing an unusual feature of the APMS sample or a genuine underlying phenomenon, clustering problem/pathological gambling in certain PSUs. Finally, our results cannot be generalized to countries lacking the community diffusion of gambling typical of the UK (Planzer, Gray, \& Shaffer, 2014). Consideration should be given by local planning authorities to limiting access to gaming machines operators in specific geographic areas. Prevention programs might be targeted at 
localities characterized by contextual determinants, similarly to other addictive disorders

(Carrà, Scioli, Monti, \& Marinoni, 2006; Gruenewald, 2007; Carrà et al., 2015). 


\section{References}

- Astbury, G., \& Turstain-Goodwin, M. (2015). Contextualising machine gambling characteristics by location - final report A spatial investigation of machines in bookmakers using industry data. Retrieved from:

http://www.responsiblegamblingtrust.org.uk/media/1170/b2gamingmachines_finalreport 20150218.pdf.

- Auger, N., Lo, E., Cantinotti, M., \& O'Loughlin, J. (2010). Impulsivity and socioeconomic status interact to increase the risk of gambling onset among youth. Addiction, 105, 2176-2183. doi: 10.1111/j.1360-0443.2010.03100.x.

- Austin, P.C. (2010). Estimating multilevel logistic regression models when the number of clusters is low: a comparison of different statistical software procedures. The International Journal of Biostatistics, 6, 16. doi: 10.2202/1557-4679.1195.

- Brazier, J. E., \& Roberts, J. (2004). The estimation of a preference-based measure of health from the SF-12. Medical Care, 42, 851-859.

- Canale, N., Vieno, A., Bowden-Jones, H., \& Billieux, J. (2017). The benefits of using the UPPS model of impulsivity rather than the Big Five when assessing the relationship between personality and problem gambling. Addiction, 112, 372-373. doi: 10.1111/add.13641.

- Carrà, G., Crocamo, C., Borrelli, P., Popa, I., Ornaghi, A., Montomoli, C., Clerici, M. (2015). Correlates of dependence and treatment for substance use among people with comorbid severe mental and substance use disorders: findings from the "Psychiatric and Addictive Dual Disorder in Italy (PADDI)" Study. Comprehensive Psychiatry, 58,152159. doi: 10.1016/j.comppsych.2014.11.021.

- Carrà, G., Crocamo, C., Bartoli, F., Carretta, D., Schivalocchi, A., Bebbington, P.E., \& Clerici, M. (2016). Impact of a Mobile E-Health Intervention on Binge Drinking in Young People: The Digital-Alcohol Risk Alertness Notifying Network for Adolescents and Young Adults Project. The Journal of Adolescent Health, 58, 520-526. doi: 10.1016/j.jadohealth.2016.01.008.

- Carrà, G., Crocamo, C., Borrelli, P., Tabacchi, T., Bartoli, F., Popa, I., ... Clerici M. (2017). Area-level deprivation and adverse consequences in people with substance use disorders: findings from the psychiatric and addictive dual disorder in Italy (PADDI) study. Substance Use \& Misuse, 52, 451-458. doi: 10.1080/10826084.2016.1240696. 
- Carrà, G., Scioli, R., Monti, M. C., Marinoni, A. (2006). Severity profiles of substanceabusing patients in Italian community addiction facilities: Influence of psychiatric concurrent disorders. European Addiction Research, 12, 96-101. doi: $10.1159 / 000090429$.

- Christakis, N. A., \& Fowler, J. H. (2013). Social contagion theory: Examining dynamic social networks and human behavior. Statistics in Medicine, 32, 556-577. doi: 10.1002/sim.5408.

- Cowlishaw, S., \& Hakes, J. K. (2015). Pathological and problem gambling in substance use treatment: Results from the National Epidemiologic Survey on Alcohol and Related Conditions (NESARC). The American Journal on Addictions, 24, 467-474. doi: 10.1111/ajad.12242.

- Cowlishaw, S., \& Kessler, D. (2016). Problem Gambling in the UK: Implications for Health, Psychosocial Adjustment and Health Care Utilization. European Addiction Research, 22, 90-98. doi: 10.1159/000437260.

- DCLG-Department for Communities and Local Government. (2004). Communities and neighbourhoods: Indices of deprivation 2004. Retrieved from http://webarchive.nationalarchives.gov.uk/20100410180038/http://www.communities.go v.uk/archived/general-content/communities/indicesofdeprivation/216309/.

- Fairer gambling. (2015). STOP the FOBTs Campaign, 2015. Retrieved from: http://www.stopthefobts.org/; http://fairergambling.org/.

- Gainsbury, S. M., Russell, A., Hing, N., Wood, R., \& Blaszczynski, A. (2013). The impact of internet gambling on gambling problems: A comparison of moderate-risk and problem Internet and non-Internet gamblers. Psychology of Addictive Behaviors, 27, 1092-1101. http://dx.doi.org/10.1037/a0031475.

- Grant, J. E., \& Chamberlain, S. R. (2015). Gambling disorder and its relationship with substance use disorders: Implications for nosological revisions and treatment. The American Journal on Addictions, 24, 126-131. doi: 10.1111/ajad.12112.

- Greenland, S., Mansournia, M. A., \& Altman, D. G. (2016). Sparse data bias: a problem hiding in plain sight. BMJ, 352, i1981. doi: 10.1136/bmj.i1981.

- Griffiths, M., Wardle, H., Orford, J., Sproston, K., \& Erens B. (2009). Sociodemographic correlates of internet gambling: findings from the 2007 British gambling prevalence survey. CyberPsychology \& Behavior, 12, 199-202. doi: 10.1089/cpb.2008.0196. 
- Gruenewald, P.J. (2007). The spatial ecology of alcohol problems: Niche theory and assortative drinking. Addiction, 102, 870-878. doi: 10.1111/j.1360-0443.2007.01856.x.

- Haushofer, J., \& Fehr, E. (2014). On the psychology of poverty. Science, 344, 862-867. doi: $10.1126 /$ science.1232491.

- Hilbe, J. M. (2009).Logistic Regression Models (p.259). Chapman \& Hall/CRC: Series Texts in Statistical Science.

- Jiménez-Murcia, S., Alvarez-Moya, E. M., Stinchfield, R., Fernández-Aranda, F., Granero, R., Aymamí, N., ... Menchón, J.M. (2010). Age of onset in pathological gambling: clinical, therapeutic and personality correlates. Journal of Gambling Studies, 26, 235-48. doi: 10.1007/s10899-009-9175-3.

- Johansson, A., Grant, J. E., Kim, S. W., Odlaug, B. L., \& Götestam, K. G. (2009). Risk Factors for Problematic Gambling: A Critical Literature Review. Journal of Gambling Studies, 25, 67-92. doi: 10.1007/s10899-008-9088-6.

- Lewis, G., Pelosi, A. J., Araya, R., \& Dunn, G. (1992). Measuring psychiatric disorder in the community: a standardized assessment for use by lay interviewers. Psychological Medicine, 22, 465-486. doi: 10.1017/S0033291700030415.

- Livingstone, C. (2001). The social economy of Poker Machine Gambling in Victoria. International Gambling Studies, 1, 45-65. doi: 10.1080/14459800108732287.

- Malgady, R. G., Rogler, L. H., \& Tryon, W. W. (1992). Issues of validity in the Diagnostic Interview Schedule. Journal of Psychiatric Research, 26, 59-67. doi: 10.1016/0022-3956(92)90016-H.

- Mann, R. E. (2005). Availability as a law of addiction. Addiction, 100, 924-925. doi: 10.1111/j.1360-0443.2005.01146.x.

- Martins, S. S., Storr, C. L., Lee, G. P., \& Ialongo N. S. (2013). Environmental influences associated with gambling in young adulthood. Journal of Urban Health, 90, 130-140. doi: 10.1007/s11524-012-9751-1.

- McManus, S., Meltzer, H., Brugha, T. S., Bebbington, P. E., \& Jenkins, R. (Eds). (2009). Adult Psychiatric Morbidity in England, 2007: Results of a Household Survey. Leeds, The NHS Information Centre for Health and Social Care.

- Miers, D. (2006). Implementing Great Britain's Gambling Act 2005: The Gambling Commission and the Casino Question. Gaming Law Review, 10, 472-481. doi:10.1089/glr.2006.10.472. 
- Pavlou, M., Ambler, G., Seaman, S. R., Guttmann, O., Elliott, P., King, M., \& Omar, R. Z. (2015). How to develop a more accurate risk prediction model when there are few events. BMJ, 351, h3868. doi: 10.1136/bmj.h3868. Erratum in: (2016) BMJ, 353, i3235.

- Pearce, J., Mason, K., Hiscock, R., \& Day, P. (2008). A national study of neighbourhood access to gambling opportunities and individual gambling behaviour. Journal of Epidemiology \& Community Health, 62, 862-868. doi: 10.1136/jech.2007.068114.

- Planzer, S., Gray, H. M., \& Shaffer, H. J. (2014). Associations between national gambling policies and disordered gambling prevalence rates within Europe. International Journal of Law and Psychiatry, 37, 217-229. doi: 10.1016/j.ijlp.2013.11.002.

- Ryder, A. G., Costa, P. T., \& Bagby, R. M. (2007). Evaluation of the SCID-II personality disorder traits for DSM-IV: Coherence, discrimination, relations with general personality traits, and functional impairment. Journal of Personality Disorders, 21, 626-637. doi:10.1521/pedi.2007.21.6.626.

- Saunders, J. B., Aasland, O. G., Babor, T. F., Dela Fuente, J. R., \& Grant, M. (1993). Development of the Alcohol Use Disorders Identification Test (AUDIT): WHO collaborative project on early detection of persons with harmful alcohol consumption, part II. Addiction, 88, 791-804. Doi: 10.1111/j.1360-0443.1993.tb02093.x.

- Shaffer, H.J., \& Korn, D.A. (2002). Gambling and related mental disorders: a public health analysis. Annual Review of Public Health, 23, 171-212. doi: 10.1146/annurev.publhealth.23.100901.140532.

- Slutske, W. S., Deutsch, A. R., Statham, D. J., \& Martin, N. G. (2015). Local area disadvantage and gambling involvement and disorder: Evidence for gene-environment correlation and interaction. Journal of Abnormal Psychology, 124, 606-622. doi: 10.1037/abn0000071.

- Stockwell, T., Sitharan, T., McGrath, D., \& Lang, E. (1994). The measurement of alcohol dependence and impaired control in community samples. Addiction, 89, 167-174. doi: 10.1111/j.1360-0443.1994.tb00875.x.

- Vittinghoff, E., \& McCulloch, C.E. (2007). Relaxing the rule of ten events per variable in logistic and Cox regression. American Journal of Epidemiology, 165, 710-718. doi: 10.1093/aje/kwk052.

- Wardle, H., Keily, R., Astbury, G., \& Reith, G. (2014a). 'Risky places?': mapping gambling machine density and socio-economic deprivation. Journal of Gambling Studies, 30, 201-212. doi: 10.1007/s10899-012-9349-2. 
- Wardle, H., Moody, A., Spence, S., Orford, J., Volberg, R., Jotangia, D., ... Dobbie, F.; National Centre for Social Research, Gambling Commission. (2011). British Gambling Prevalence Survey 2010. National Centre for Social Research. The Stationery Office: London. Retrieved from http://www.rgtinfohub.org.uk/wpcontent/uploads/2015/10/british-gambling-prevalence-survey-2010.pdf

- Wardle, H., Seabury, C., Ahmed, H., Payne, C., Bryon, C., Corbett, J., \& Sutton, R. (2014b). Gambling behaviour in England \& Scotland: Findings from the health survey for England 2012 and Scottish Health Survey 2012. London: The Gambling Commission.

- Welte, J. W., Wieczorek, W. F., Barnes, G. M., Tidwell, M. C., \& Hoffman, J. H. (2004). The relationship of ecological and geographic factors to gambling behavior and pathology. Journal of Gambling Studies, 20, 405-423. doi: 10.1007/s10899-004-4582-y.

- Wheeler, B. W., Rigby, J., \& Huriwai, T. (2006). Pokies and poverty: Problem gambling risk factor geography in New Zealand. Health Place, 12, 86-96. doi: 10.1016/j.healthplace.2004.10.011.

- Whiteside, S. P., \& Lynam, D. R. (2001). The five factor model and impulsivity: using a structural model of personality to understand impulsivity. Personality and Individual Difference, 30, 669-689. doi: 10.1016/S0191-8869(00)00064-7. 
Table 1. Descriptive statistics* of respondents by different levels of past year gambling

\begin{tabular}{|c|c|c|c|c|c|}
\hline & $\begin{array}{c}\text { Total } \\
\mathbf{N}=7328\end{array}$ & $\begin{array}{c}\text { Problem/Pathological } \\
\text { Gambling } N=41(0.6 \%)\end{array}$ & $\begin{array}{l}\text { Recreational gambling } \\
\mathrm{N}=4774(65 \%)\end{array}$ & $\begin{array}{c}\text { No gambling } \\
\mathbf{N}=\mathbf{2 5 1 3}(\mathbf{3 4 \%})\end{array}$ & $\mathbf{P}$ \\
\hline Gender (Female) & $4167(56.86 \%)$ & $9(21.95 \%)$ & $2571(53.85 \%)$ & $1587(63.15 \%)$ & $<0.001^{\mathrm{a}}$ \\
\hline Age yrs. mean (SD) & $51.05(18.52)$ & $45.51(18.96)$ & $50.55(17.58)$ & $52.10(20.15)$ & $0.002^{\mathrm{b}}$ \\
\hline Education & & & & & $<0.001^{\mathrm{a}}$ \\
\hline Degree, teaching, HND, nursing & $1910(7.38 \%)$ & $6(14.64 \%)$ & $1121(23.93 \%)$ & $783(31.87 \%)$ & \\
\hline A level & $933(12.73 \%)$ & $10(24.39 \%)$ & $662(14.13 \%)$ & $261(10.39 \%)$ & \\
\hline GCSE or equivalent & $1803(24.60 \%)$ & $8(19.51 \%)$ & $1260(26.89 \%)$ & $535(21.29 \%)$ & \\
\hline Foreign/other & $283(3.86 \%)$ & 0 & $176(3.76 \%)$ & $107(4.26 \%)$ & \\
\hline No qualifications & $2252(30.73 \%)$ & $15(36.59 \%)$ & $1466(31.29 \%)$ & $771(30.68 \%)$ & \\
\hline Marital status (Married/Cohabiting) & $4102(55.98 \%)$ & $16(39.02 \%)$ & $2803(58.71 \%)$ & $1283(51.05 \%)$ & $<0.001^{\mathrm{a}}$ \\
\hline Unemployed (economically inactive) & $3361(45.87 \%)$ & $19(46.34 \%)$ & $1978(41.43 \%)$ & $1364(54.28 \%)$ & $<0.001^{\mathrm{a}}$ \\
\hline Financial difficulties & & & & & \\
\hline Debt & $591(8.06 \%)$ & $12(29.27 \%)$ & $362(7.63 \%)$ & $217(8.64 \%)$ & $<0.001^{\mathrm{a}}$ \\
\hline Borrow & $588(8.02 \%)$ & $10(24.39 \%)$ & $397(8.36 \%)$ & $181(7.20 \%)$ & $<0.001^{\mathrm{a}}$ \\
\hline Social support $\left(\mathrm{N}^{\circ}\right.$ close relatives/friends) mean $(S D)$ & $12.9(9.5)$ & $9.9(5.7)$ & $13.1(9.3)$ & $12.7(9.8)$ & $0.001^{\mathrm{b}}$ \\
\hline median (interquartile range $25 \%$ ile $75 \%$ ile) & $10[7-16]$ & $9[5-12]$ & $11[7-16]$ & $10[6-16]$ & \\
\hline Household annual total income $£$ mean $(S D)$ & $28606.4(30171.1)$ & $39467.0(114223.3)$ & $28699.1(27942.0)$ & $28229.24(31285.6)$ & $0.003^{\mathrm{b}}$ \\
\hline QIMD deprivation quintiles & & & & & $0.001^{\mathrm{a}}$ \\
\hline 1. $\quad 0.59-8.35$ (least deprived) & $1405(19.17 \%)$ & $3(7.32 \%)$ & $868(18.18 \%)$ & $534(21.25 \%)$ & \\
\hline 2. $8.35-13.72$ & $1627(22.20 \%)$ & $3(7.32 \%)$ & $1088(22.79 \%)$ & $536(21.33 \%)$ & \\
\hline 3. $13.72-21.16$ & $1448(19.76 \%)$ & $8(19.51 \%)$ & $948(19.86 \%)$ & $492(19.58 \%)$ & \\
\hline 4. $21.16-34.21$ & $1377(18.79 \%)$ & $11(26.83 \%)$ & $915(19.17 \%)$ & $451(17.95 \%)$ & \\
\hline 5. $34.21-86.36$ (most deprived) & $1471(20.07 \%)$ & $16(39.02 \%)$ & $955(20.00 \%)$ & $500(19.90 \%)$ & \\
\hline Self-rated health & & & & & $<0.001^{\mathrm{a}}$ \\
\hline Excellent/very good & $3597(49.09 \%)$ & $13(31.71 \%)$ & $2379(49.84 \%)$ & $1205(47.95 \%)$ & \\
\hline Good & $2063(28.15 \%)$ & $10(24.39 \%)$ & $1376(28.83 \%)$ & $677(26.94 \%)$ & \\
\hline Fair/poor & $1665(22.72 \%)$ & $18(43.90 \%)$ & $1018(21.33 \%)$ & $629(25.03 \%)$ & \\
\hline Common mental disorder (CMD) & $1167(15.9 \%)$ & $17(41.46 \%)$ & $723(15.14 \%)$ & $427(16.99 \%)$ & $<0.001^{\mathrm{a}}$ \\
\hline Impulsivity & $2246(30.6 \%)$ & $23(62.16 \%)$ & $1547(33.03 \%)$ & $676(26.9 \%)$ & $<0.001^{\mathrm{a}}$ \\
\hline Suicidal ideation & $331(4.5 \%)$ & $8(19.51 \%)$ & $199(4.17 \%)$ & $124(4.9 \%)$ & $<0.001^{\mathrm{a}}$ \\
\hline Suicide attempts & $376(5.1 \%)$ & $9(21.95 \%)$ & $225(4.72 \%)$ & $142(5.6 \%)$ & $<0.001^{\mathrm{a}}$ \\
\hline Alcohol & & & & & $<0.001^{\mathrm{a}}$ \\
\hline no hazardous alcohol use & $6298(85.9 \%)$ & $26(63.41 \%)$ & $4022(84.25 \%)$ & $2250(89.5 \%)$ & \\
\hline hazardous use but no dependency & $667(9.1 \%)$ & $6(14.63 \%)$ & $483(10.12 \%)$ & $178(7.1 \%)$ & \\
\hline alcohol dependency & $363(4.9 \%)$ & $9(21.95 \%)$ & $269(5.63 \%)$ & $85(3.4 \%)$ & \\
\hline Smoking & $1659(22.6 \%)$ & $17(41.46 \%)$ & $1180(24.72 \%)$ & $462(18.4 \%)$ & $<0.001^{\mathrm{a}}$ \\
\hline Drug misuse & $533(7.3 \%)$ & $11(28.21 \%)$ & $358(7.51 \%)$ & $164(6.5 \%)$ & $<0.001^{\mathrm{a}}$ \\
\hline
\end{tabular}

"There are missing values for some variables: the greatest numbers of missing values is for impulsivity and education, with 7174 and 7181 ratings, respectively.

a Pearson chi-square test; ${ }^{\text {b }}$ Kruskal-Wallis test 
Table 2. Multilevel mixed-effects logistic regression models for problem/pathological and any other gambling

\begin{tabular}{|c|c|c|c|c|}
\hline & Problem/pathological gambling ${ }^{\mathrm{a}}$ & & Recreational gambling $^{\mathbf{b}}$ & \\
\hline & OR $(95 \% \mathrm{CI})$ & $\mathbf{P}$ & OR $(95 \% \mathrm{CI})$ & $\mathbf{P}$ \\
\hline Intercept & $0.002(0.0002$ to 0.017$)$ & $<0.001$ & $1.241(0.961$ to 1.602$)$ & 0.098 \\
\hline Gender (Female) & $0.203(0.085$ to 0.486$)$ & $<0.001$ & $0.741(0.665$ to 0.826$)$ & $<0.001$ \\
\hline Age & $1.006(0.980$ to 1.033$)$ & 0.632 & $1.006(1.002$ to 1.009$)$ & 0.002 \\
\hline Marital status (Married/Cohabiting) & $0.862(0.404$ to 1.839$)$ & 0.701 & $1.350(1.211$ to 1.506$)$ & $<0.001$ \\
\hline Unemployed (economically inactive) & $0.559(0.235$ to 1.328$)$ & 0.188 & $0.584(0.515$ to 0.661$)$ & $<0.001$ \\
\hline Financial difficulties (debt) & $2.248(0.806$ to 6.271$)$ & 0.122 & $0.763(0.614$ to 0.949$)$ & 0.015 \\
\hline Financial difficulties (borrow) & $1.355(0.474$ to 3.872$)$ & 0.571 & $1.363(1.086$ to 1.710$)$ & 0.008 \\
\hline Social support & $0.969(0.925$ to 1.015$)$ & 0.184 & $1.002(0.996$ to 1.008$)$ & 0.461 \\
\hline \multicolumn{5}{|l|}{ Self-rated health ${ }^{1}$} \\
\hline Good & $1.094(0.422$ to 2.832$)$ & 0.854 & $1.103(0.973$ to 1.252$)$ & 0.126 \\
\hline Fair or poor & $2.073(0.787$ to 5.464$)$ & 0.140 & $0.960(0.828$ to 1.113$)$ & 0.591 \\
\hline Common mental disorder (CMD) & $1.550(0.658$ to 3.650$)$ & 0.316 & $0.883(0.757$ to 1.031$)$ & 0.115 \\
\hline Impulsivity & $2.590(1.231$ to 5.446$)$ & 0.012 & 1.275 (1.136 to 1.432$)$ & $<0.001$ \\
\hline \multicolumn{5}{|l|}{ Alcohol $^{2}$} \\
\hline hazardous use, no dependency & $1.613(0.621$ to 4.190$)$ & 0.326 & $1.308(1.080$ to 1.584$)$ & 0.006 \\
\hline alcohol dependency & $1.617(0.585$ to 4.474$)$ & 0.355 & $1.406(1.069$ to 1.848$)$ & 0.015 \\
\hline Smoking & $0.817(0.354$ to 1.885$)$ & 0.636 & $1.490(1.298$ to 1.710$)$ & $<0.001$ \\
\hline Drug misuse & $2.677(1.056$ to 6.785$)$ & 0.038 & $0.934(0.748$ to 1.167$)$ & 0.550 \\
\hline \multicolumn{5}{|l|}{ QIMD Deprivation quintiles ${ }^{3}$} \\
\hline $8.35-13.72$ & $0.480(0.078$ to 2.938$)$ & 0.427 & $1.259(1.069$ to 1.484$)$ & 0.006 \\
\hline $13.72-21.16$ & $1.389(0.333$ to 5.794$)$ & 0.652 & $1.246(1.050$ to 1.478$)$ & 0.012 \\
\hline $21.16-34.21$ & $2.125(0.542$ to 8.329$)$ & 0.279 & $1.286(1.077$ to 1.535$)$ & 0.005 \\
\hline $34.21-86.36$ (most deprived) & 2.622 (0.694 to 9.916$)$ & 0.155 & $1.352(1.127$ to 1.622$)$ & 0.001 \\
\hline Random effects component & Estimate (SE) & & Estimate (SE) & \\
\hline Level 2 (PSU-Area) variance & $0.507(0.852)$ & & $0.095(0.029)$ & \\
\hline Residual intra-class correlation (ICC) & $0.133(0.194)$ & & $0.029(0.008)$ & \\
\hline
\end{tabular}

Base outcome: ano problem/pathological gambling ${ }^{b}$ no gambling. OR=Odds Ratio.

Reference categories for dummy variables: ${ }^{1}$ Excellent/very good; ${ }^{2}$ no hazardous alcohol use; ${ }^{3}$ least deprived 